\title{
Parques de bairro na cidade média de Santa Maria, RS, Brasil: planejamento urbano e percepção dos usuários
}

\author{
Parques de barrio en la ciudad media de Santa Maria, RS, \\ Brasil: planificación urbana y percepción de los usuarios
}

\section{Neighbourhood parks in the medium-sized city of Santa Maria, RS, Brazil: urban planning and user perception}

\author{
Alice Rodrigues Lautert \\ alicelautert@gmail.com \\ Universidade Federal de Santa Maria, UFSM, Santa Maria, RS \\ Luís Guilherme Aita Pippi \\ guiamy@hotmail.com \\ Universidade Federal de Santa Maria, UFSM, Santa Maria, RS
}

Resumo: Os parques de bairro de Santa Maria, município do interior do Rio Grande do Sul, pertencem ao sistema de espaços livres da cidade, que se encontra desconectado e com lacunas de distribuição no perímetro urbano. Nesse artigo é ressaltado o papel do planejador urbano na gestão desses espaços, a fim de identificar as deficiências e capacidades locais de forma produtiva e eficiente. Será apresentado também uma metodologia quali-quantitativa através de um questionário online, que buscou obter a percepção e preferência da população sobre os parques de bairro. Esse diálogo com a comunidade se mostra uma relevante ferramenta que pode colaborar de maneira efetiva para com a gestão dos espaços livres das cidades médias.

Palavras-chave: parques; espaços livres; gestão; preferência.

Resumen: Los parques de barrio de Santa Maria, municipio del interior del Rio Grande do Sul, pertenecen al sistema de espacios libres de la ciudad, que se encuentra desconectado y con brechas de distribución en el perímetro urbano. En este artículo se resalta el papel del planificador urbano en la gestión de esos espacios, a fin de identificar las deficiencias y capacidades locales de forma productiva y eficiente. Se presentará también una metodología cual-cuantitativa a través de un cuestionario online, que buscó obtener la percepción y preferencia de la población sobre los parques de barrio. Este diálogo con la comunidad se muestra una relevante herramienta que puede colaborar de manera efectiva con la gestión de los espacios libres de las ciudades medias.

Palabras clave: parques; espacios libres; gestión; preferencia.

Abstract: The neighbourhood parks of Santa Maria, a municipality in the interior of Rio Grande do Sul, belong to the free space system of the city, which is disconnected from distribution gaps in the urban perimeter. In this paper, the role of the urban planner in the management of these spaces is highlighted, in order to identify the local deficiencies and capacities in a productive and efficient way. A qualitative-quantitative methodology will also be presented through an online questionnaire, which sought 
to obtain the perception and preference of the population about the neighbourhood parks. This dialogue with the community is an important tool that can effectively collaborate with the management of free spaces in medium-sized cities.

Keywords: parks; free spaces; management; preference.

\section{INTRODUÇÃO}

Santa Maria é uma cidade média localizada no estado do Rio Grande do Sul e possui, segundo o último recenseamento do IBGE (2010), 261.031 habitantes. Sua identidade cultural inclui características referentes ao grande número de universitários, à presença do segundo maior regimento militar do país e ao passado ferroviário. É conhecida também como a cidade "coração do Rio Grande do Sul", por estar situada no centro do estado (Fig. 1).

Figura 1: Localização da cidade de Santa Maria, no centro do estado do Rio Grande do Sul.

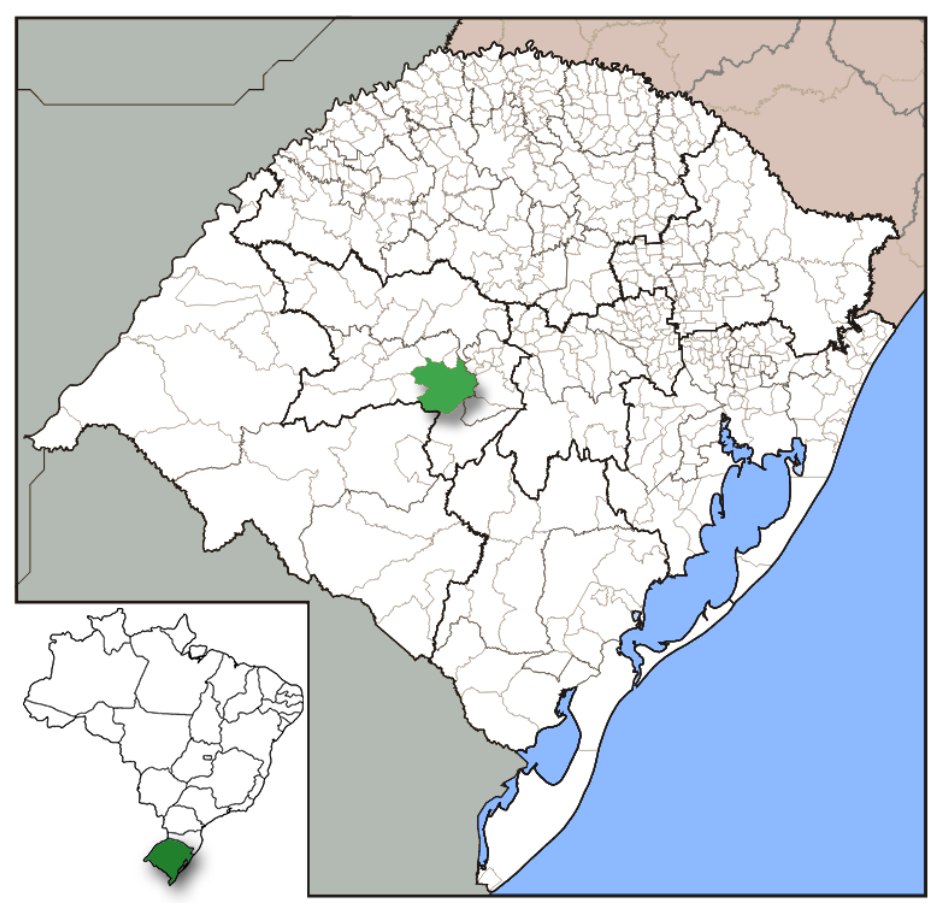

Fonte: adapt. de Abreu, 2006.

Os espaços livres de lazer e recreação da cidade, como os parques e praças da cidade, não possuem grandes conexões dentro de um sistema geral, assim como há certo desequilíbrio na sua distribuição na área urbana. Do contrário, concentram-se em sua maioria no centro da cidade, enquanto certos bairros possuem número reduzido desses espaços.

Esse estudo retrata a situação dos parques de bairro da cidade, quanto à sua localização e distribuição na área urbana e sua atual condição dentro do sistema de espaços livres de Santa Maria. É apresentado também os dados levantados junto à população sobre sua percepção e preferência entre os quatro parques de bairro existentes na cidade, Parque Itaimbé, Parque da Medianeira, Parque CACISM e Parque Jockey Club. 


\section{REFERENCIAL TEÓRICO}

\section{Cidades Médias}

Segundo Sposito (2007), as cidades médias podem ser compreendidas analisando sua situação geográfica, pela distância em relação às cidades de maior porte e pelo número de cidades pequenas em sua área de influência. Para os moradores dos grandes centros urbanos, as cidades médias passam certo encanto devido a seus menores índices de criminalidade, reduzido tempo de deslocamento até o trabalho e baixos níveis de poluição (AMORIM FILHO; SERRA, 2001; ANGEOLETTO et al., 2016). Por outro lado, as cidades médias tendem a reproduzir automaticamente padrões morfológicos e culturais de grandes cidades, como a propagação de condomínios fechados com mais opções de segurança e lazer (AMORIM, 2015).

Em função das novas dinâmicas territoriais, muitas cidades médias têm passado por redefinição de suas estruturas internas, que decorrem da constituição de novas centralidades e formas de usos e apropriações do espaço urbano (KAIMOTI, 2009). O planejador urbano deve ser capaz de identificar as lacunas e capacidades locais para lidar com os espaços livres e edificados das cidades médias de forma produtiva e eficiente, propondo diretrizes coerentes com a realidade das cidades médias (ANGEOLETTO; FELLOWES; SANTOS, 2018; ANGEOLETTO et al., 2019; RUMBLE et al., 2019).

\section{Parques urbanos}

Os parques urbanos surgiram durante a urbanização e industrialização das cidades no século XIX (SILVA; PASQUALETTO, 2013), como opção de lazer e recreação para as elites em meio aos espaços edificados. Woudstra (2018) destaca que o pioneiro paisagista urbano Patrick Geddes (1854-1932) defendia a importância de planejar parques e jardins como uma necessidade de saúde, salubridade e bem-estar dos habitantes da cidade (2018). Sobre as origens dos parques urbanos, Scalise explana a respeito:

No final do século XVIII, na Inglaterra, o parque surge como fato urbano relevante e tem seu pleno desenvolvimento no século seguinte, com ênfase maior na reformulação de Haussmann em Paris, e o Movimento dos Parques Americanos - o Park Moviment liderado por Frederick Law Olmstead e seus trabalhos em New York, Chicago e Boston. No século XIX surgiram os grandes jardins contemplativos, os parques de paisagem, os parkways, os parques de vizinhança americanos e os parques franceses formais e monumentais (SCALISE, 2002, p.18).

Macedo e Sakata (2010) descrevem o parque urbano como um espaço livre público estruturado por vegetação, que tem como um de seus papeis atender ao lazer e recreação da massa urbana, sendo que esses espaços estão em constante processo de recodificação. Destacam também que as cidades brasileiras contemporâneas necessitam de novos parques, geralmente de dimensões menores devido à escassez de área disponível e alto custo da terra. 
Os parques podem ser identificados como espaços livres com infraestrutura, mobiliário urbano e paisagismo dentro de aglomerados urbanos (BENINI; MARTIN, 2011), os quais podem ser encontrados tanto em pequenas, como em médias e grandes cidades. Entretanto, o parque urbano contemporâneo traz em si a contradição de fugir exatamente do urbano, ao reproduzir um espaço que detém conceitos opostos aos que a cidade atual representa: uma área livre, aberta, com a sensação de ar puro, sem carros, com pessoas passando o tempo e crianças brincando (SAKATA, 2018).

Quanto às funções dos parques, eles conseguem atender grande diversidade de solicitações, não apenas contemplativas, mas também ativas como lazer e recreação, esportivas, culturais e conservação de recursos naturais (MACEDO; SAKATA, 2010). Tais espaços possuem grande relevância para as cidades, pois contribuem para a qualidade ambiental, social e cultural e trazem vitalidade ao espaço urbano. Os parques também propiciam o encontro entre os cidadãos, contribuindo para a sustentabilidade do tecido social urbano e abrandam as tensões sociais ao viabilizar a aproximação do ser humano com a natureza, o encontro e a integração entre os moradores da cidade. $\mathrm{O}$ ambiente natural e agradável desses espaços tenta minimizar os problemas das cidades e é extremamente benéfico para seus habitantes.

Percebe-se a proliferação de parques no atual contexto de transformações urbanas e nova legislação ambiental, com intuito de preservar recursos naturais existentes ou providenciar espaços de lazer e esporte que valorizem os bairros que recebem novos empreendimentos (SAKATA, 2018). Os parques surgem como propostas atraentes em novos projetos urbanos, porém se espera que estejam inseridos harmonicamente na rede de espaços livres, bem como dialoguem de maneira coerente com o entorno imediato.

\section{Classificação de parques urbanos}

Segundo a classificação de Rosa Kliass e Miranda Magnolli (2006), os parques urbanos podem ser classificados com base nas atividades propiciadas e em suas áreas de abrangência (Quadro 1).

Os parques de bairro constituem uma categoria de parques urbanos que merecem especial atenção por suas dimensões intermediárias entre praças e parques setoriais ou metropolitanos. Assim, tais parques podem manter um diálogo equilibrado com a comunidade e oferecer diversas oportunidades de encontro entre vizinhos, além do lazer e recreação. Parques nessa escala são mais frequentes em cidades médias. 
Quadro 1: Categorias de parques urbanos.

\begin{tabular}{|l|l|l|}
\hline Tipo de parque & Característica & $\begin{array}{l}\text { Raio máximo de } \\
\text { atendimento }\end{array}$ \\
\hline Pocket park & lote em meio ao tecido urbano destinado à recreação passiva de todas as idades & $250 \mathrm{~m}$ \\
\hline $\begin{array}{l}\text { Parque de } \\
\text { vizinhança }\end{array}$ & $\begin{array}{l}\text { áreas verdes destinadas à recreação ativa de crianças de } 0 \text { a } 10 \text { anos e à } \\
\text { recreação passiva; }\end{array}$ & $500 \mathrm{~m}$ \\
\hline Parque de bairro & $\begin{array}{l}\text { áreas verdes destinadas à recreação ativa de jovens de } 11 \text { a } 24 \text { anos e à } \\
\text { recreação passiva; }\end{array}$ & $1.000 \mathrm{~m}$ \\
\hline Parque setorial & $\begin{array}{l}\text { áreas verdes destinadas à recreação ativa e passiva de toda a população do } \\
\text { município, com equipamentos para utilização em fins de semana; }\end{array}$ & $5.000 \mathrm{~m}$ \\
\hline $\begin{array}{l}\text { Parque } \\
\text { metropolitano }\end{array}$ & $\begin{array}{l}\text { áreas verdes destinadas à recreação ativa e passiva de toda a região } \\
\text { metropolitana, localizados nas reservas florestais junto de represas. }\end{array}$ & $10.000 \mathrm{~m}$ \\
\hline
\end{tabular}

Fonte: adapt. de Kliass e Magnoli, 2006.

\section{SITUAÇÃO DOS PARQUES DE BAIRRO DE SANTA MARIA}

O Plano Diretor de Desenvolvimento Territorial (PDDT) vigente em Santa Maria foi sancionado em julho de 2018. Após revisão e discussões sobre o plano anterior, o documento aprovado tem como objetivo "ordenar o pleno desenvolvimento das funções sociais do território e garantir a melhor qualidade de vida de seus habitantes" (PMSANTA MARIA, 2018). A Lei de Uso e Ocupação do Solo (LUOS) prevê Áreas Especiais de Conservação Natural, entre as quais o Parque Itaimbé e Parque da Medianeira são citados, porém sem especificidades de planejamento. Há referência sobre áreas preferenciais para uso de parques nos novos loteamentos, em que 15\% deve ser destinado a área verde. É prevista a criação de um Sistema de Áreas Livres do Município no PDDT, dentro da seção que trata da política de manejo dos recursos naturais, com lançamento de diretrizes gerais, porém sem maiores detalhes a respeito desse sistema.

No ano de 2010 foi lançado pelo Escritório da Cidade (atual Instituto de Planejamento) o programa Parques para Santa Maria. O documento do programa traz informações sobre as áreas naturais da cidade e reconhece a necessidade de implantação do Sistema de Áreas Livres através da proposta de revitalizar os parques existentes e criação de novos parques. Dentro do programa são destacados parques tidos como prioritários, como meio de instituir a política de manejo dos recursos naturais urbanos do PDDT, entre eles o Parque Jockey Club. Após tentativas da equipe de buscar recursos e profissionais interessados em colaborar com a efetivação dos projetos, infelizmente as propostas não foram levadas adiante.

Conforme a hierarquia de parques proposta por Kliass e Magnoli (2006) é possível classificar os parques existentes em Santa Maria e projetar seus raios de atendimento na área urbana (Fig. 2). 
Figura 2: Distribuição dos parques existentes dentro do perímetro urbano de Santa Maria, RS.

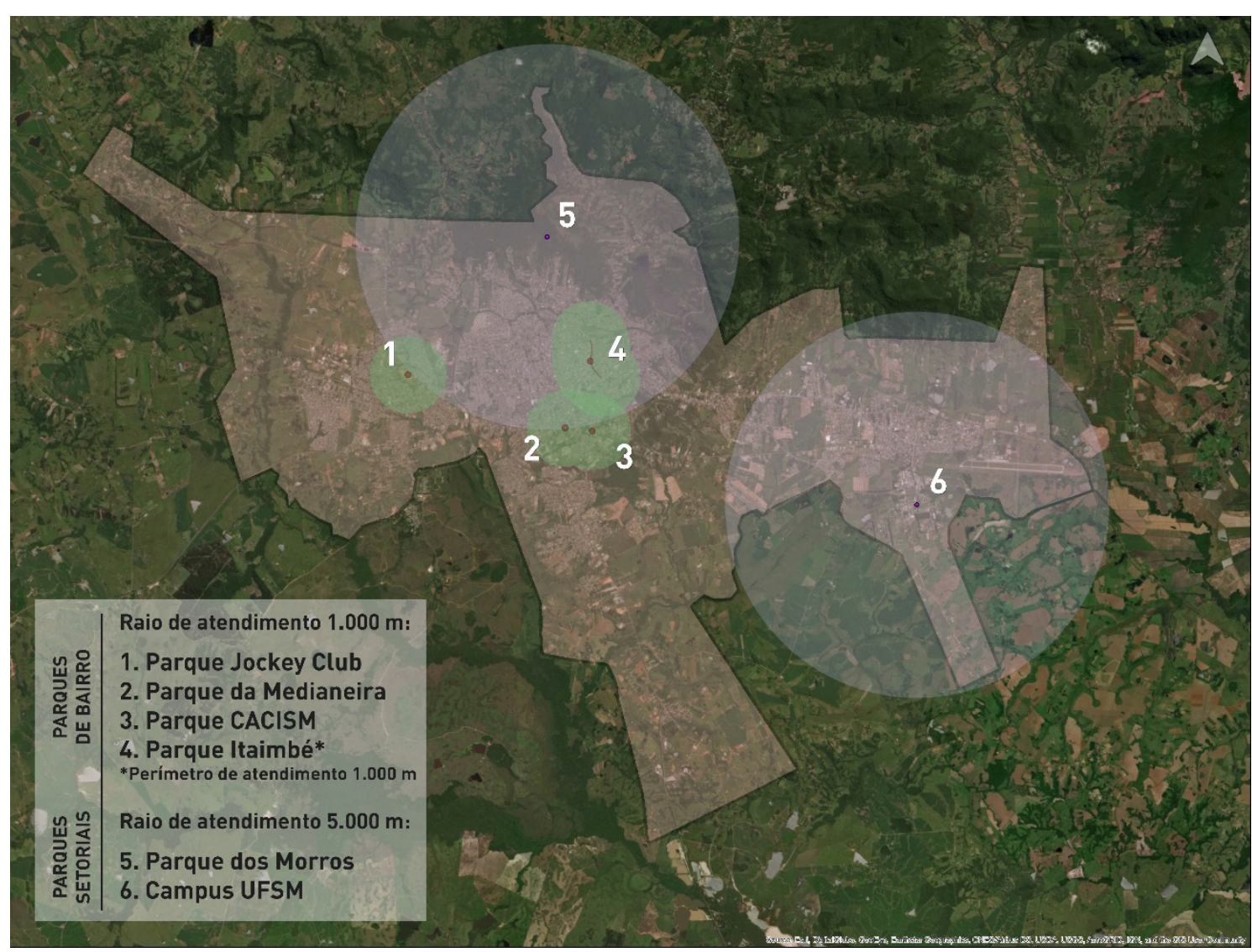

Fonte: os autores através do ArcMap 10.4.1.

Pode-se identificar dois Parques Setoriais na cidade, o Parque dos Morros, localizado na zona norte, e o Campus da Universidade Federal de Santa Maria (UFSM), no extremo leste. O Parque dos Morros é uma área natural coberta pela vegetação típica do bioma Mata Atlântica, rico em biodiversidade da fauna e flora local. Segundo o Sistema Nacional de Unidades de Conservação (SNUC), pode ser enquadrado na categoria "Parque Natural Municipal", em que a área pode ser utilizada de forma sustentável e conservada ao mesmo tempo (BRASIL, 2011). Já o Campus da UFSM tem sido amplamente utilizado para realização de atividades culturais, exercícios físicos, lazer e recreação. Suas áreas livres e vegetadas estão disponíveis não apenas para os usuários da UFSM, mas para toda a comunidade, que tem respondido de maneira positiva ao se apropriar do espaço.

A respeito dos Parques de Bairro, três são localizados em área mais central e o mais afastado, Parque Jockey Club, na zona oeste. Situado no bairro Juscelino Kubitschek, este parque está cercado por bairros de classe média e baixa. Foi originado da desativação do Jockey Club, com sua área destinada para abrigar eventos ao ar livre, como o Festival Internacional de Balonismo, realizado entre 2009 e 2016. O parque recebeu nova infraestrutura, como estacionamento, pista de caminhada, academia ao ar livre, playground e quadras poliesportivas. Possui uma bela perspectiva e vista natural dos morros que contornam a cidade ao norte. Porém não foi revegetado com árvores, o que torna a paisagem árida; 
também há falhas na manutenção da infraestrutura, fazendo com que seja pouco utilizado pela comunidade (Fig. 3).

Figura 3: Pórtico de entrada do Parque Jockey Club (A), mobiliário e quadras poliesportivas ao fundo (B).

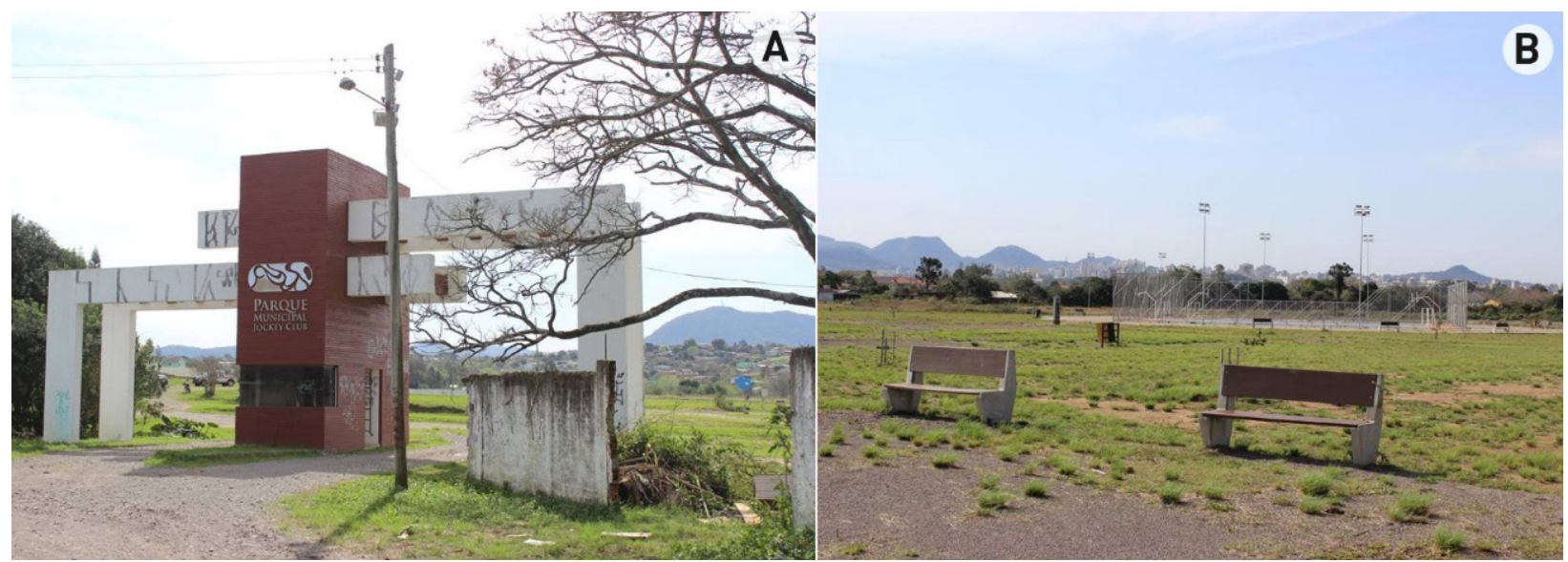

Fonte: os autores, 2016.

O Parque da Medianeira, por sua vez, se encontra no bairro Nossa Senhora da Medianeira e é uma área cercada privada pertencente ao Santuário Basílica Nossa Senhora da Medianeira, cujo altar monumento é tombado como patrimônio histórico e cultural do município (PM Santa Maria, 2017). A área verde do parque é em grande parte livre, sem grande mobiliário fixo, o que a torna um espaço flexível para realização de eventos (Fig. 4). Pode-se perceber visuais interessantes da cidade devido ao declive acentuado do terreno. Seus momentos de maior público são ao entardecer e aos fins de semana, surgindo como opção de lazer e recreação para famílias e jovens com e sem animais de estimação, porém o espaço carece de alguns equipamentos como sanitários públicos.

Figura 4: Altar monumento da Basílica da Medianeira, Santa Maria, RS, com morros ao fundo (A) e evento sediado no parque em feriado (B).

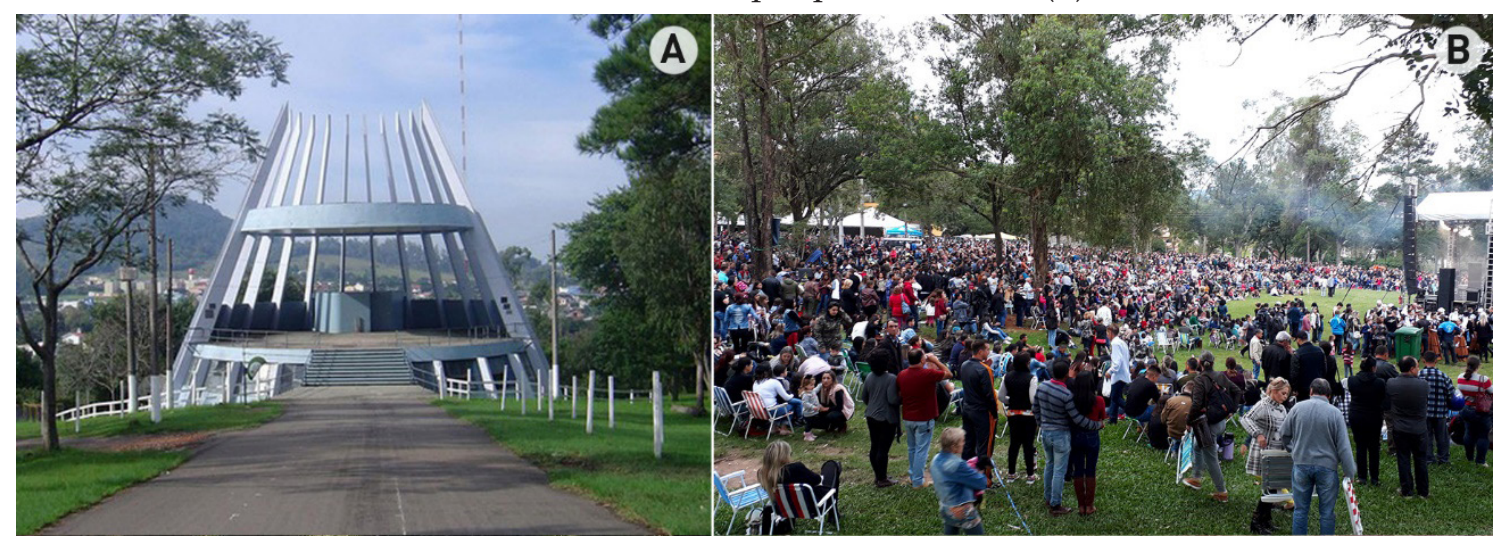

Fonte: PM de Santa Maria, 2017 (A) e autores, 2018 (B).

O Parque CACISM (Câmara de Comércio, Indústria e Serviços de Santa Maria) está localizado no bairro Nonoai, próximo da Estação Rodoviária de Santa Maria. Assim como o Parque da Medianeira, trata-se de um espaço privativo com horário de abertura e 
fechamento variáveis conforme as estações do ano. O parque possui pista de caminhada, ciclovia, academia ao ar livre, playground, estacionamento, mobiliário e extensa área gramada. A maior parte de seu perímetro é contornada por um córrego e sua mata ciliar, caracterizados como Área de Preservação Permanente (APP), resguardada por cercas, o que não impede, porém, o sombreamento em grande parte da pista de caminhada e ciclovia (Fig. 5). A maioria dos usuários do Parque CACISM usa o espaço para prática de exercícios físicos, havendo também a presença de famílias com crianças e jovens em seus momentos de lazer e recreação.

Figura 5: Parque CACISM possui academia ao ar livre (A) e APP protegida em um dos acessos (B).

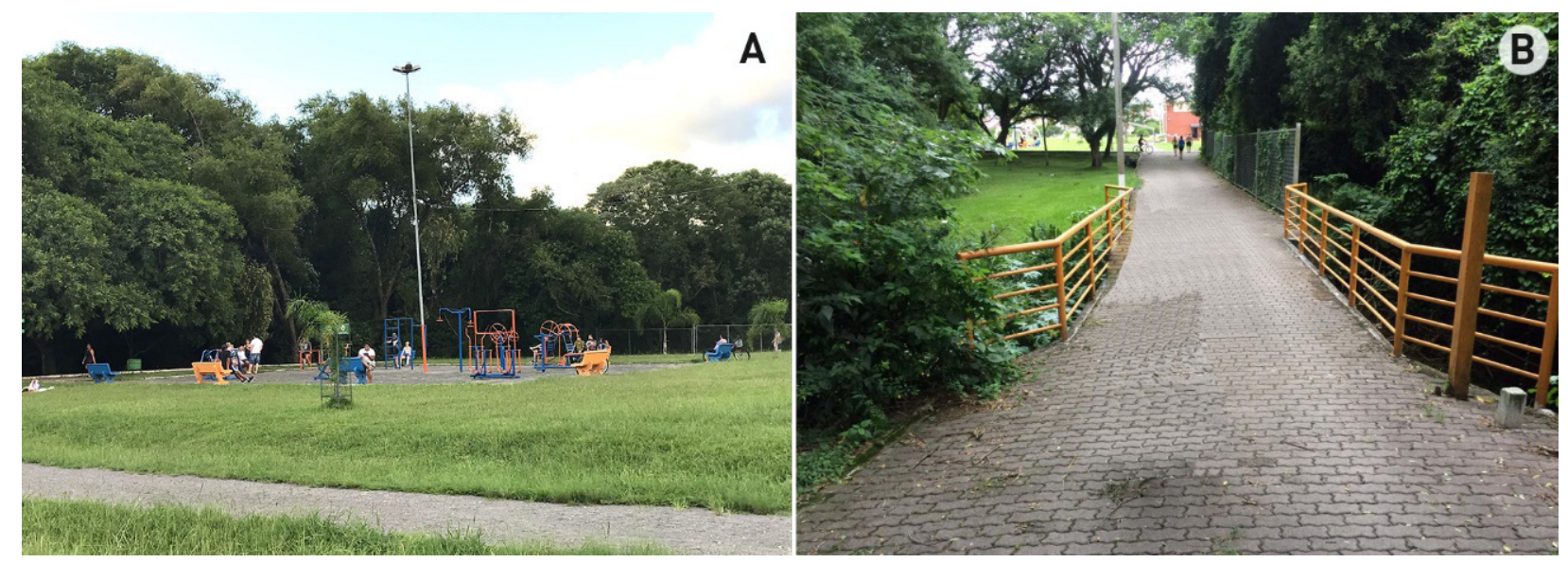

Fonte: os autores.

Já o Parque Itaimbé se encontra na região central de Santa Maria e é um dos principais e mais conhecidos espaços públicos da cidade devido à sua localização. Originário do Arroio Itaimbé, que foi canalizado, o parque está em cota inferior às vias limítrofes e por sua longa extensão pode ser caracterizado como parque linear. Possui pista multiuso, quadras poliesportivas, playground, áreas gramadas livres, estação de parkour, centro cultural e concha acústica (Fig. 6). Porém devido à falta de manutenção do mobiliário e equipamentos urbanos e à iluminação pública deficiente ou inexistente, o parque tem transmitido grande sensação de insegurança, principalmente nos períodos noturnos, reduzindo assim a presença de usuários. 
Figura 6: Parque Itaimbé possibilita práticas de atividades físicas e uso da área como passagem no centro da cidade (A), assim como sedia eventos (B).

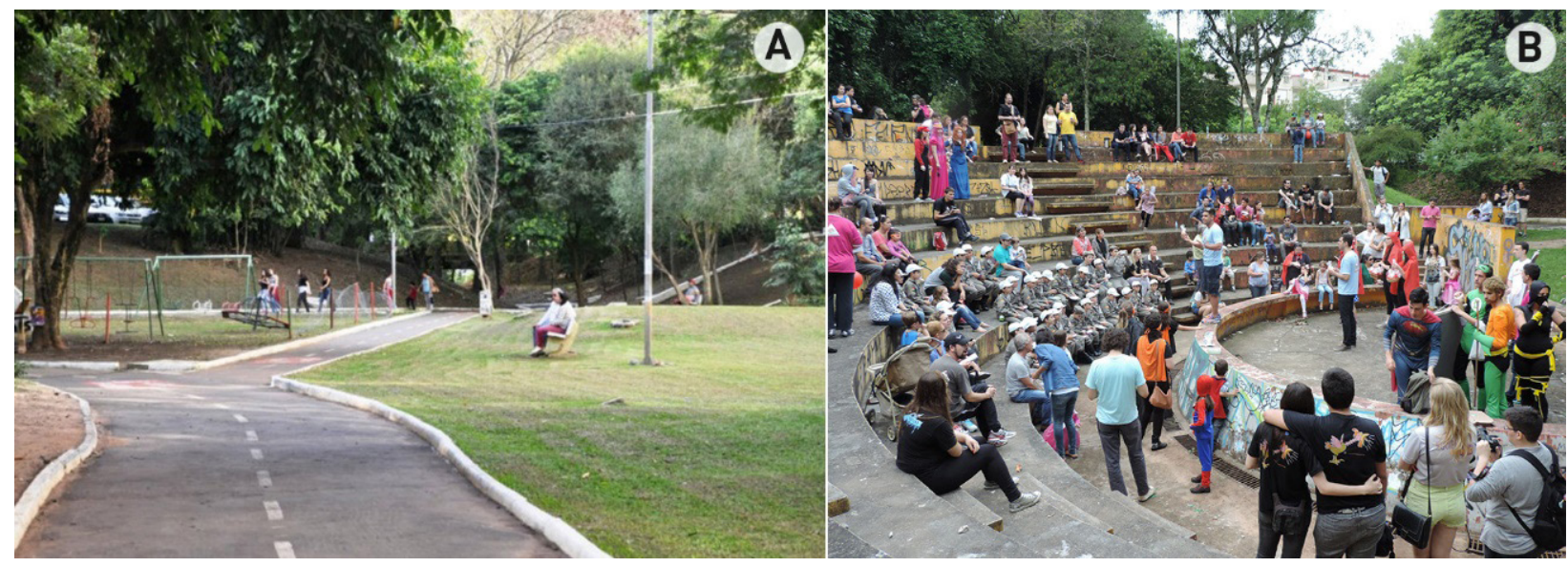

Fonte: PM de Santa Maria, 2015 (A) e autores, 2016 (B).

Através da análise espacial da localização dos parques de Santa Maria percebe-se lacunas na distribuição desses espaços livres na malha urbana. As zonas oeste e sul não são contempladas, exigindo um maior deslocamento para chegar usufruir dos parques existentes. O atual PDDT não contempla discussões sobre áreas em potencial para criação de futuros parques ou uma retomada do programa anterior de revitalização dos parques existentes. Sendo Santa Maria uma cidade média, mesmo com um número razoável de parques, é desejável atender efetivamente a população, viabilizando acesso aos espaços livres.

Portanto apresenta-se uma metodologia de análise que dialoga com a população para levantar a percepção acerca dos quatro parques de bairro da cidade. Retrata também como tem ocorrido a utilização desses espaços para a compreensão de sua dinâmica na cidade de Santa Maria.

\section{METODOLOGIA}

Foi utilizada a pesquisa qualiquantitativa por meio de um questionário online respondido de maneira anônima. Através das redes sociais, o usuário se deparava com uma breve descrição dos parques de bairro e respondia questões de caráter aberto e fechado sobre seu perfil (gênero, faixa etária e bairro de residência em Santa Maria). Era então solicitado que enumerasse, em ordem de preferência, os parques conforme sua percepção pessoal (sendo 1 o de maior preferência; 4 o de menor preferência), também assinalando os parques porventura desconhecidos pelo usuário.

O usuário era direcionado, então, a responder perguntas a respeito do parque assinalado como o de maior preferência. Era questionado sobre o motivo de ter selecionado determinada preferência, quais atividades realizadas nesse parque, ou a razão de não realizar algumas. Através de perguntas fechadas respondia qual o(s) dia(s) e período de utilização deste parque e, para finalizar, era solicitado a indicar aspectos positivos e negativos do parque. 


\section{RESULTADOS}

No total 95 pessoas participaram do questionário sobre os parques de bairro da cidade, sendo a maioria mulheres adultas (Fig. 7). A maioria reside no bairro Centro (37\%), seguido pelo bairro Camobi (20\%), porém, de uma forma geral, percebe-se que foi possível atingir grande parte da cidade Fig. 8).

Figura 7: Informações sobre o perfil dos usuários respondentes ao questionário online.
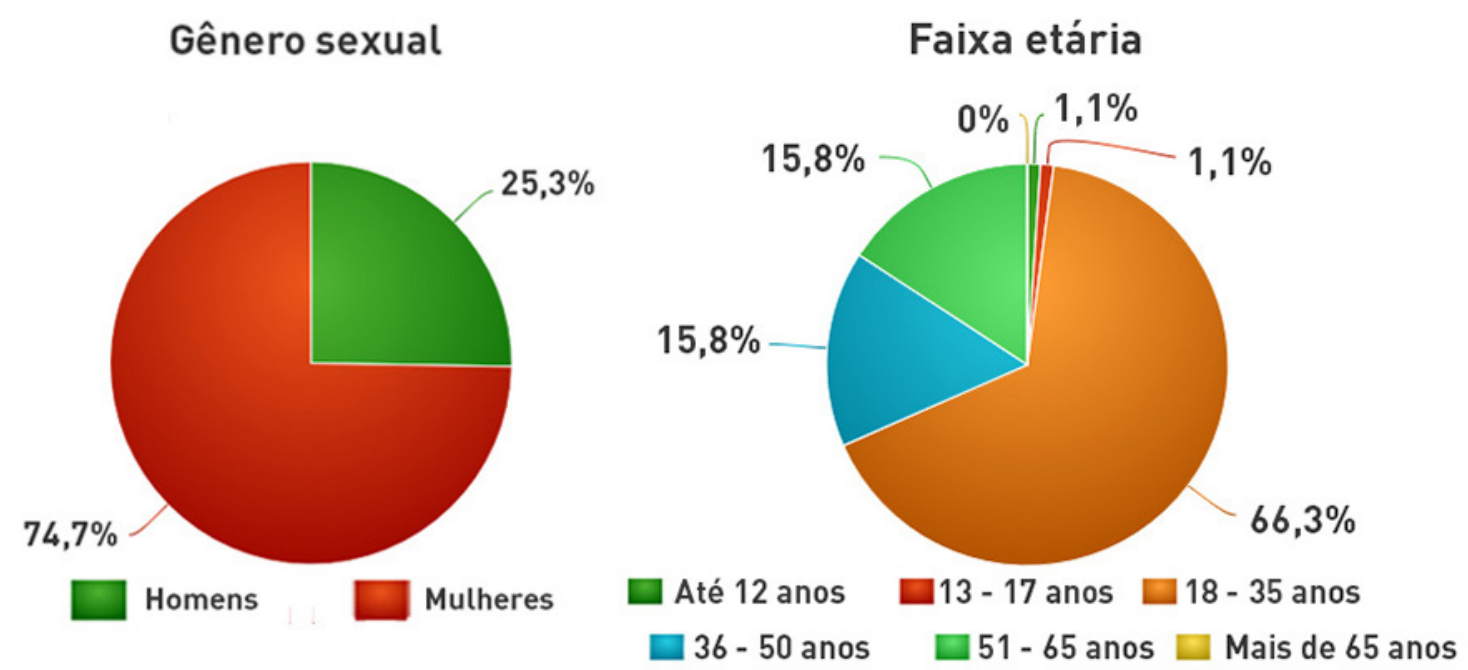

Fonte: os autores.

Figura 8: Bairros abrangidos pelos usuários.

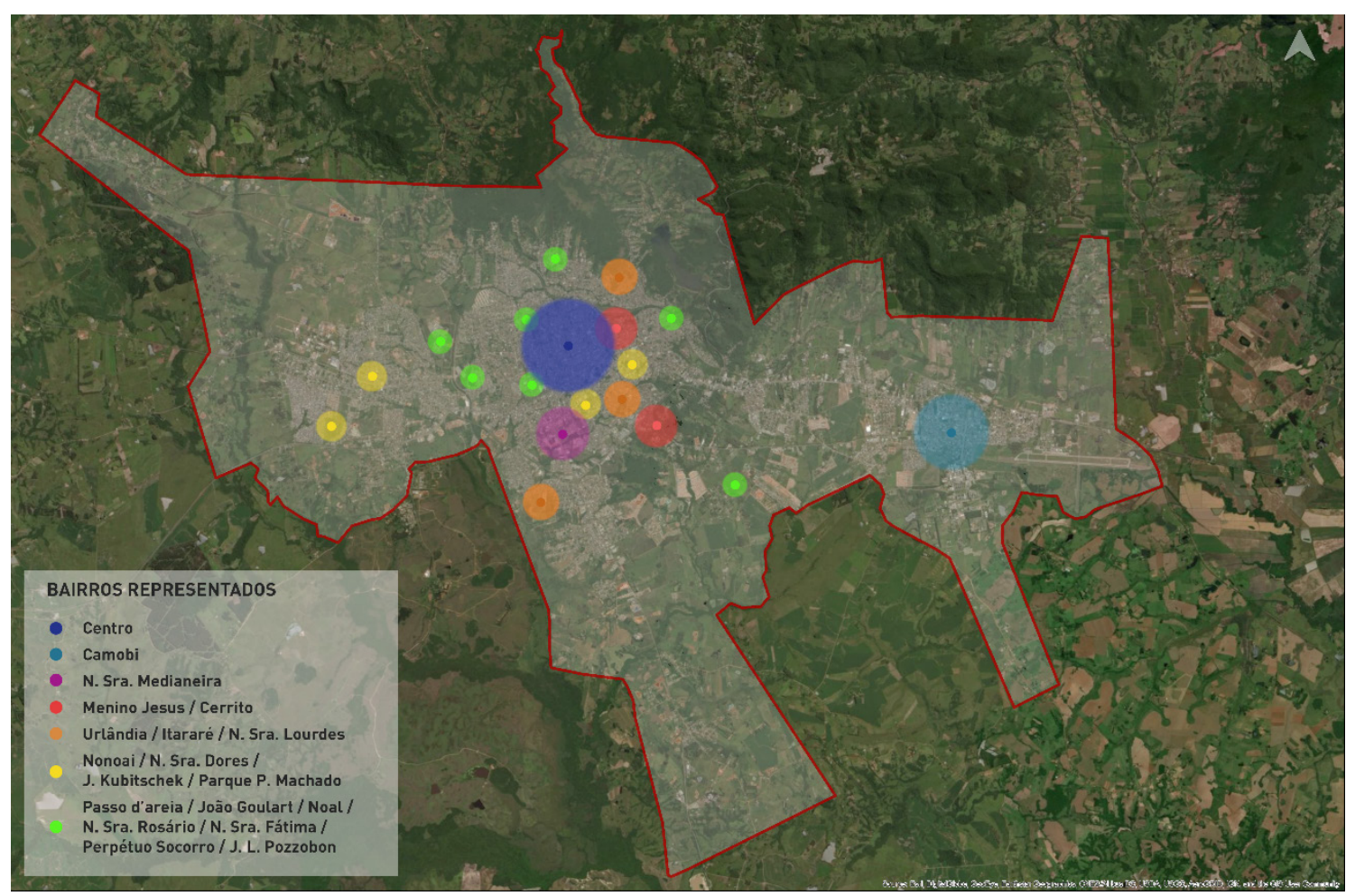

Fonte: os autores. 
O objetivo do questionário era compreender qual dos parques de bairro da cidade era o de maior preferência pela população. A Figura 9 ilustra que o Parque Itaimbé foi apontado como o preferido, seguido pelo Parque da Medianeira. O gráfico demonstra também que, para surpresa dos pesquisadores, grande parte do público desconhece os parques CACISM e Jockey Club. Quando questionados através de uma pergunta fechada com opções sobre os motivos que levaram a escolha dos parques de preferência, a maioria se deve à proximidade com a residência dos usuários e o desejo de ter contato com a natureza, seguido pela prática de atividades físicas nesses espaços (Fig. 10).

Figura 9: Posição dos parques em ordem de preferência pelos usuários.

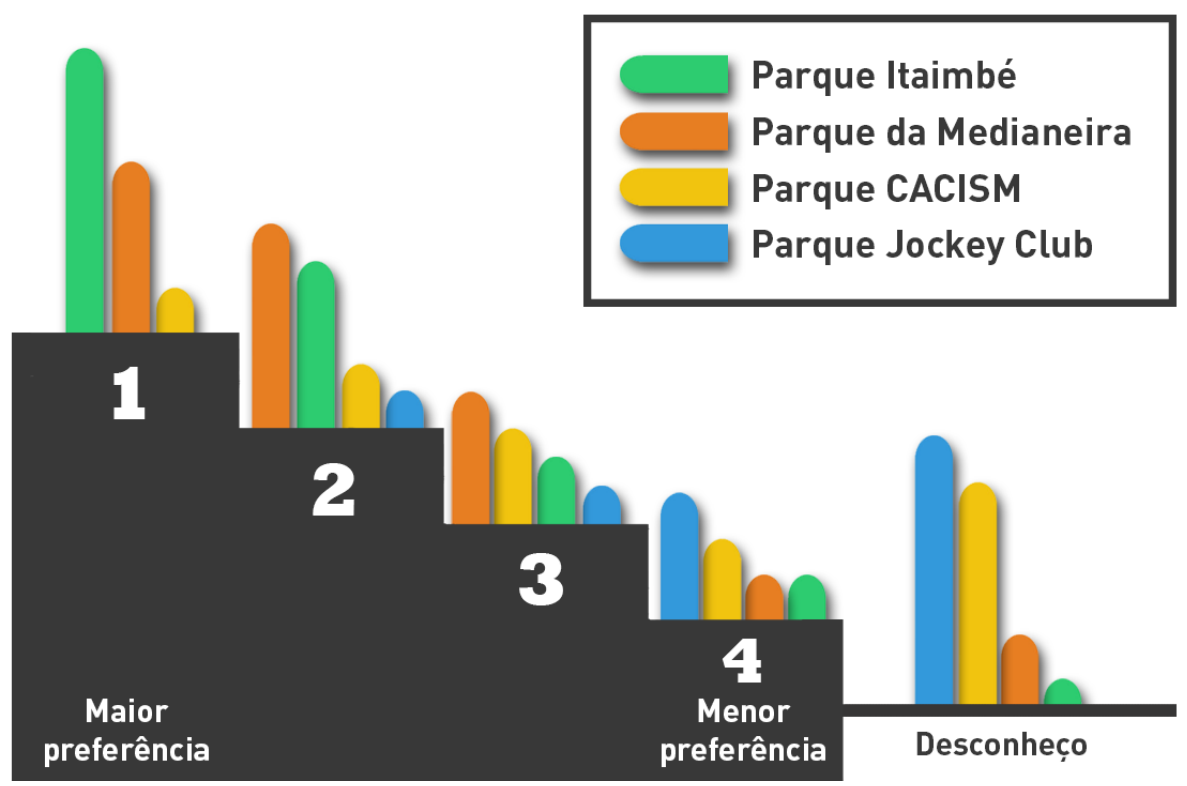

Fonte: os autores.

Figura 10: Principais motivos que levam os usuários ao seu parque de maior preferência.

Motivos que levam você a frequentar o parque:

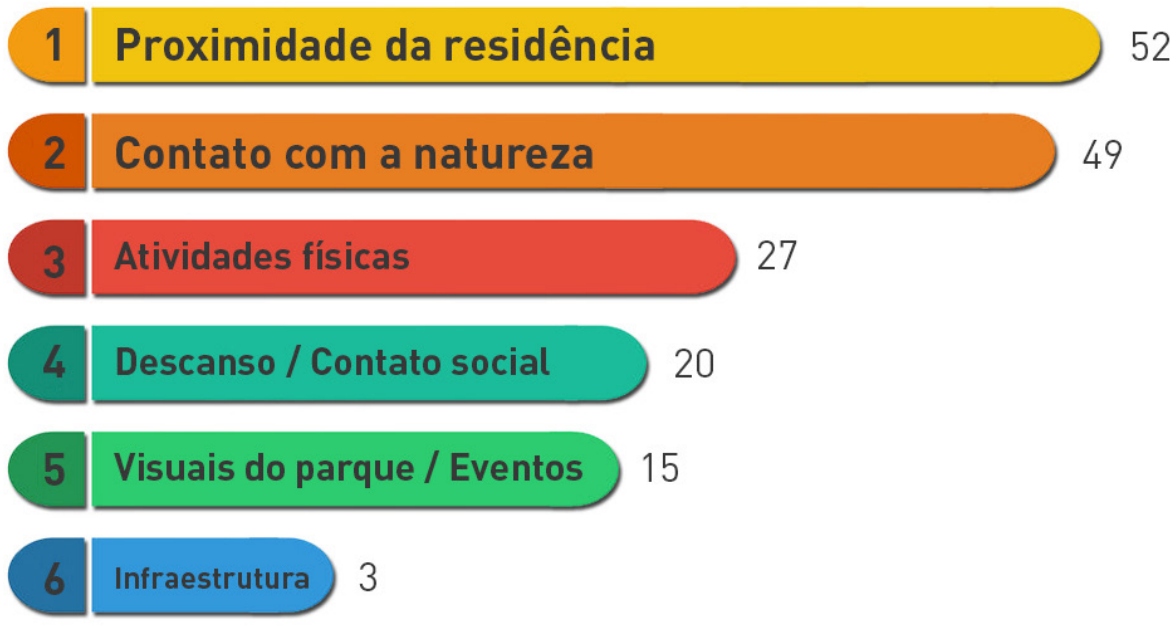

Fonte: os autores. 
Quanto ao período de utilização, o público costuma ir ao parque de na maior parte das vezes durante as tardes e nos fins de semana (Figs. 11 e 12).

Figura 11: Período do dia de maior utilização do parque de maior preferência.

\section{Em que período do dia você costuma ir ao parque?}

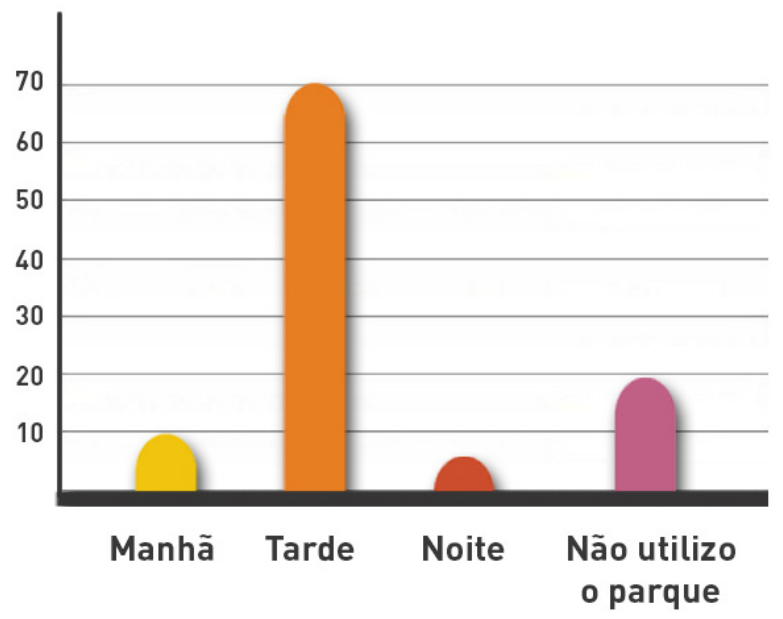

Fonte: os autores.

Figura 12: Período na semana de maior utilização do parque de maior preferência.

Em que período da semana você costuma ir ao parque?

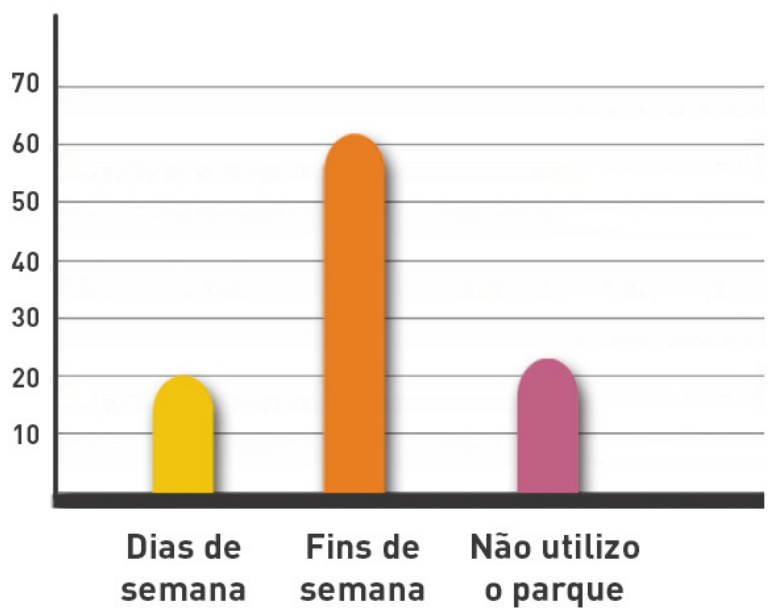

Fonte: os autores, 2019.

Para dados qualitativos, obtidos através das perguntas abertas, foram detectadas palavras-chave, conforme sugere Henkel (2017), referentes aos parques Itaimbé e da Medianeira, os de maior preferência pela população questionada. Com relação ao Parque Itaimbé, preferido em geral por sua localização, a maioria realiza caminhadas, encontro entre amigos e para tomar chimarrão, frequentar o bar e passear com animal de estimação (Fig. 13). 
Figura 13: Motivações sobre o Parque Itaimbé e atividades ali realizadas pelos usuários.

Por que você escolheu esse como parque preferido?

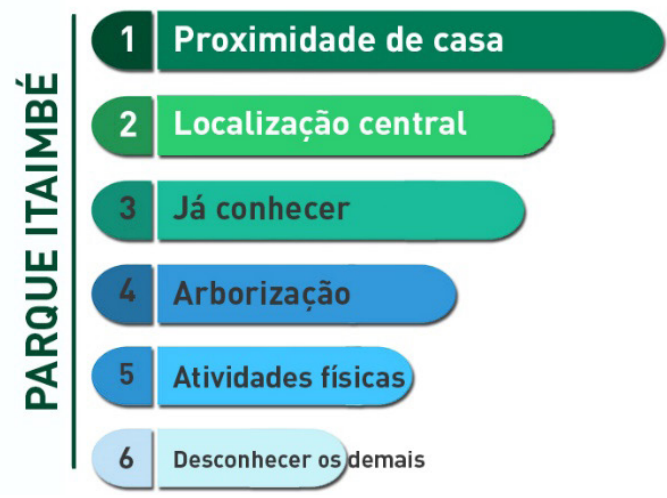

Que atividades você faz nesse parque?

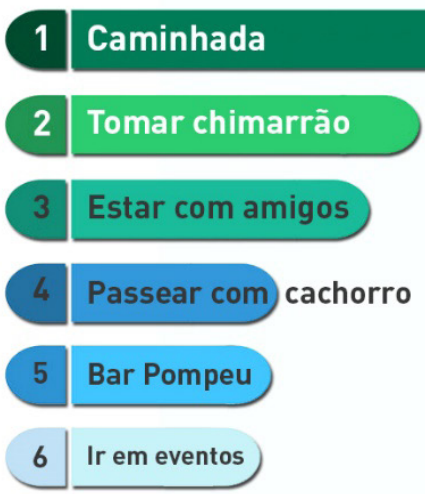

Fonte: os autores.

No Parque da Medianeira, a escolha se deu principalmente ao fator segurança, seguido pela proximidade com a residência. Alguns destacaram ainda o espaço amplo, a arborização, limpeza e tranquilidade do parque. As atividades mais citadas remetem ao hábito sulino de tomar chimarrão, assim como as caminhadas, encontro com amigos e passeio com animal de estimação (Fig. 14).

Figura 14: Motivações sobre o Parque da Medianeira e atividades realizadas pelos usuários.
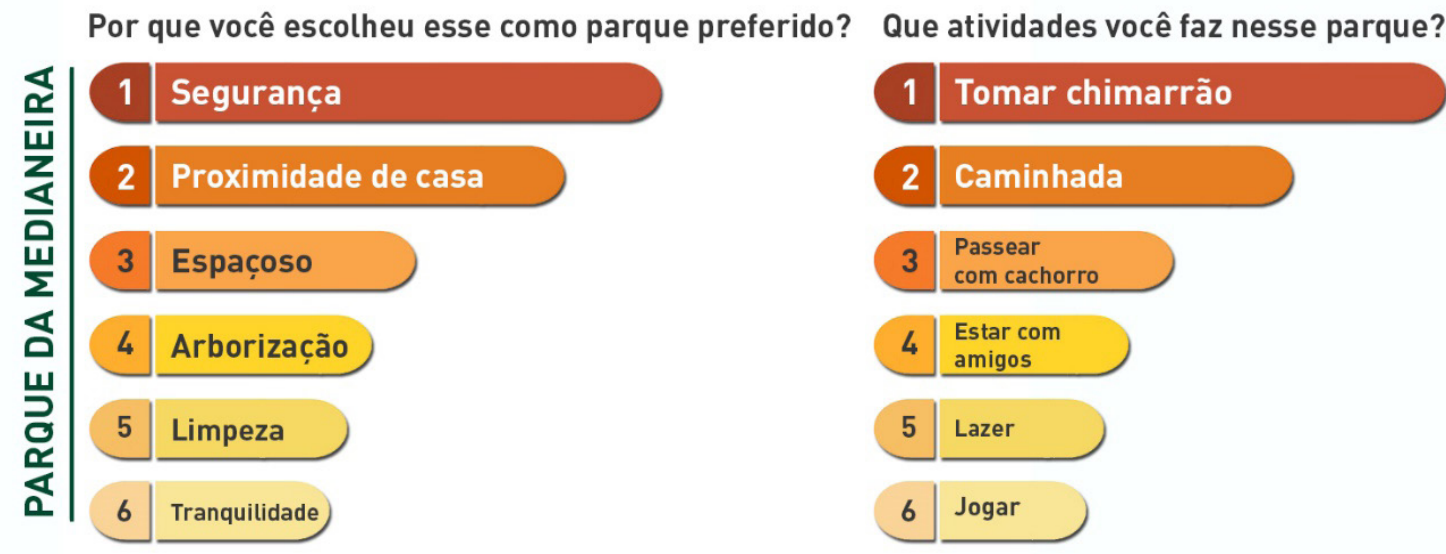

Fonte: os autores.

Escolhido por pequena parcela dos questionados como parque de sua preferência, o Parque CACISM foi elogiado pela pista de caminhada, arborização e academia ao ar livre. Devido a se tratar de um espaço com grande potencial para realização de atividades físicas, melhorias poderiam ser feitas em sua infraestrutura. O Parque Jockey Club não figurou em nenhum momento como parque de maior preferência da população questionada, percebendo-se a população não está familiarizada com esta área, ainda que esta possua grande potencial como espaço livre na cidade.

A Figura 15 resume o panorama das respostas obtidas para cada parque de bairro, em que se destacam os pontos positivos e negativos citados. 
Figura 15: Panorama geral comparativo entre os quatro parques.

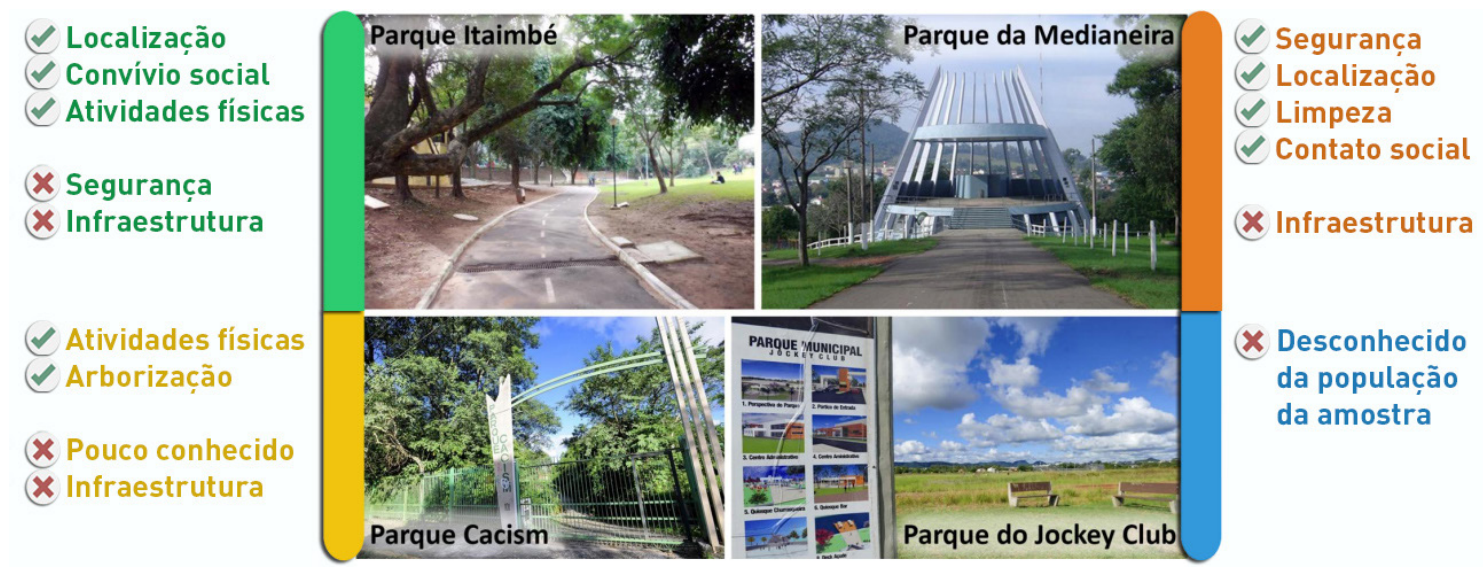

Fonte: os autores.

\section{CONCLUSÃO}

Reafirmando a relevância em refletir sobre os espaços livres urbanos, desde a etapa de planejamento até a análise de ocupação e opinião dos usuários, no caso dos parques de bairro de Santa Maria, foi possível inferir que é necessária maior atenção e diálogo sobre o planejamento urbano dos espaços livres da cidade. Esse ponto revela a importância que tais espaços representam para que a zona urbana atinja o equilíbrio entre espaços públicos e privados, assim como espaços livres e construídos, concedendo à população acesso a opções de lazer e recreação dentro do âmbito público.

Como cidade média, Santa Maria possui grande potencial em seus espaços livres abertos para a população, porém que carece ainda de especial cuidado na gestão e planejamento, a fim de valorizar o potencial existente. $\mathrm{O}$ atual sistema de espaços livres se encontra desconectado, podendo ser melhor articulado para que seja fortalecido e valorizado.

É necessário diálogo entre planejadores, técnicos e comunidade, trocando experiências e percepções, tencionando o bem comum da cidade. Como demonstrado pelo emprego do inquérito online, a opinião da população é uma ferramenta relevante que colabora com a gestão dos espaços livres, equilibradas com as possibilidades urbanísticas,

\section{REFERÊNCIAS}

ABREU, Raphael L. Localização de Santa Maria. Formato SVG. 2006. Disponível em: https://commons. wikimedia.org/wiki/File:RioGrandedoSul_MesoMicroMunicip.svg. Acesso em: 21 fev. 2019.

ANGEOLETTO, Fabio; SANTOS, Jeater W.M.C.; SANZ, J.P.R. et al. Tipología socio-ambiental de las ciudades medias de Brasil: aportes para un desarrollo urbano sostenible. Urbe -Revista Brasileira de Gestão Urbana, v. 8, n. 2, p. 272-287, 2016.

ANGEOLETTO, Fabio; FELLOWES, Mark D.; SANTOS, Jeater W.M.C. Counting Brazil's Urban Trees Will Help Make Brazil's Urban Trees Count. Journal of Forestry, v. 116, n. 5, p. 489-490, 2018. 
ANGEOLETTO, Fabio; FELLOWES, Mark D., ESSI, Liliana et al. Ecología urbana y planificación: una convergéncia ineludible. Revista Electrônica em Gestāo, Educaçāo e Tecnologia Ambiental, v. 23, e17, 2019.

AMORIM FILHO, Oswaldo; SERRA, Rodrigo V. Evolução e perspectivas do papel das cidades médias no planejamento urbano e regional. In: ANDRADE, Thomson; VALENTE, Rodrigo V. Cidades Médias Brasileiras. Rio de Janeiro: IPEA, 2001. cap. 1, p. 1-34.

AMORIM, Nayara Cristina Rosa. O sistema de espaços livres na forma urbana de Patos de Minas. Uberlândia, 2015. Dissertação (Mestrado) - Universidade Federal de Uberlândia, UFU.

BENINI, Sandra Medina; MARTIN, Encarnita Salas. Decifrando as áreas verdes públicas. Revista Formação, v. 2, n. 17, p. 63-80, 2011. Disponível em: http://revista.fct.unesp.br/index.php/formacao/ article/view/455. Acesso em: 9 nov. 2018.

BRASIL. Ministério do Meio Ambiente. SNUC - Sistema Nacional de Unidades de Conservação da Natureza: Lei $n^{\circ}$ 9.985, de 18 de julho de 2000; Decreto $n^{\circ}$ 4.340, de 22 de agosto de 2002; Decreto $n^{\circ}$ 5.746, de 5 de abril de 2006. Plano Estratégico Nacional de Áreas Protegidas: Decreto no 5.758, de 13 de abril de 2006. Brasília, 2011. Disponível em: http://www.mma.gov.br/images/arquivos/areas_protegidas/snuc/ Livro\%20SNUC\%20PNAP.pdf. Acesso em: 21 fev. 2019.

HENKEL, Karl. A categorização e a validação das respostas abertas em surveys políticos. Opinião Pública, v. 23, n. 3, 2017. Disponível em: http:// www.scielo.br/pdf/op/v23n3/1807-0191-op-23-3-0786.pdf. Acesso em: 22 fev. 2019.

IBGE - Instituto Brasileiro de Geografia e Estatística. Censo Demográfico 2010: Rio de Janeiro: 2010. Disponível em http:/ / downloads.ibge.gov.br/downloads_estatisticas.htm. Acesso em: 01 jul. 2019.

KAIMOTI, Naiara L. de A. Paisagens Vivenciadas: Apropriações Públicas dos Fundos de Vale e Sistema de Espaços Livres: Estudo de caso no Município de Bauru-SP. São Paulo, 2009. Dissertação (Mestrado em Paisagem e Ambiente) - Universidade de São Paulo, USP.

KLIASS, Rosa Grena;MAGNOLI, Miranda Martinelli. Áreas verdes derecreação. Paisageme Ambiente,n. 21, p. 245-256, 2006. Disponível em: <http://www.revistas.usp.br/paam/article/download/40254/43120>. Acesso em: 11 abr. 2018.

MACEDO, Silvio S.; SAKATA, Francine G. Parques Urbanos no Brasil. São Paulo: Ed. USP, 2010.

PM de Santa Maria. Manutenção no Parque Itaimbé: "um patrimônio de área verde que é de todos e para todos, .2015. Disponível em: http://www.santamaria.rs.gov.br/noticias/10549-manutencao-no-parqueitaimbe-ldquoum-patrimonio-de-area-verde-que-e-de-todos-e-para-todosrdquo. Acesso em: 27 fev. 2019.

PM de Santa Maria. Prefeitura tomba como patrimônio histórico e cultural o Altar Monumento da Basílica da Medianeira. Santa Maria, Maio, 2017. Disponível em: https://www.santamaria.rs.gov.br/ noticias/15060-prefeitura-tomba-como-patrimonio-historico-e-cultural-o-altar-monumento-da-basilicada-medianeira. Acesso em: 27 fev. 2019.

PM de Santa Maria. Lei Complementar n.118, de 26 de julho de 2018. Dispõe Sobre a Política de Desenvolvimento Sustentável e Sobre o Plano Diretor de Desenvolvimento Territorial do Município de Santa Maria. Santa Maria, RS, 26 jul. 2018. Disponível em: http://www.santamaria.rs.gov.br/docs/ noticia/2018/07/D27-1488.pdf. Acesso em: 20 fev. 2019.

RUMBLE, Heather; ANGEOLETTO, Fabio; CONNOP, Stuart et al. Understanding and applying ecological principles in cities. In: LEMES DE OLIVEIRA, Francisco; MELL, Ian. (Eds.). Planning Cities with Nature: Theories, Strategies and Methods. Amsterdam: Springer Nature, 2019.

SAKATA, Francine G. Parques Urbanos no Brasil: 2000 a 2017. São Paulo, 2018. Tese (Doutorado em Arquitetura e Urbanismo) - Universidade de São Paulo, USP.

SCALISE, Walnyce. Parques Urbanos - Evolução, Projeto , Funções e Usos Parques Urbanos - o Conceito Algumas definições : Parques Urbanos - Sobre as Origens Evolução do Parque Urbano no século XX Novas Tendências. Assentamentos Humanos, v. 4, n.1, p. 17-24, 2002. 
SILVA, Janaína Barbossa; PASQUALETTO, Antônio. O caminho dos parques urbanos brasileiros: da origem ao século XXI. Estudos, v. 40, n. 3, p. 287-298, 2013.

SPOSITO, Eliseu S. Reestruturação produtiva e reestruturação urbana no Estado de São Paulo. Revista Electrónica de Geografía y Ciencias Sociales, v. 11, n. 245 (69), 2007. Disponível em: <www.ub.edu/ geocrit/sn/sn-194-32.htm>. Acesso em: 7 nov. 2018.

WOUDSTRA, Jan. Designing the garden of Geddes: The master gardener and the profession of landscape architecture. Landscape and Urban Planning, v. 178, p. 198-207, 2018. https://doi.org/10.1016/j. landurbplan.2018.05.023.

Data de submissão: 28/ fev./ 2019

Data de aceite: 20/ ago./ 2019 